a statement which apparently infuriated DeGaulle.

Some contributors make reference to Monod's service during World War II in the Resistance and later in the reestablished French Army, but the volume's guidelines prevented fuller description of these parts of his life, for the same reasons the authors say little about Monod's significance as a public philosopher, illustrated by his book, Chance and Necessity, which was a sensational bestseller in France.

The essays are generally of exceptionally high quality, and they will bring back memories of great times for the large number of scientists throughout the world who have spent time with Jacques Monod and his colleagues in those laboratories built originally for Louis Pasteur. It will also bring the pleasure of enlightenment to many others who were not directly involved. In addition, for those totally outside of molecular biology, it is a worthy addition to the developing literature on the origins of this field which has so revolutionised biology. And this appearance of a memorial volume ought to stimulate interst in a more complete biography of this impressive man whose life touched so many of the important developments of the middle decades of this century.

Aaron Novick is Professor at the Institute of Molecular Biology at the University of Oregon. He spent 1953-54, 1962-63 and 1967-68 in Jacob and Monod's laboratories.

Challenge to promissory materialism

\section{Anthony Flew}

The Human Mystery. By John C. Eccles. Pp. 255. (Springer International: Berlin, Heidelberg and New York, 1979.) DM34.

Even had Sir John Eccles not begun this his own first series of Gifford Lectures with quotations from "My great master, Sherrington" (page 2) any sympathetic reviewer would have been bound to refer to the fitting facts that it was just 40 years earlier, under the same foundation and in the same University of Edinburgh, that that "great master" himself gave the lectures which were later to become Man on His Nature (Cambridge, 1940). The Human Mystery, though thoroughly worthwhile, lacks the magic of that predecessor: how could it not? The present Eccles project, of which we have here only the first and probably less distinctive half, is strictly in accordance within the terms of Lord Gifford's will: ". . . to promote and diffuse the study of Natural Theology in the widest sense of that term - in other words the knowledge of God"'.

The aim is to mount a challenge to what, following his friend Sir Karl Popper, he calls "promissory materialism", a challenge along the entire front but with the main weight concentrated in the sector of his own lifelong concentration, the human brain. Promissory materialism is defined as the "claim that science is so powerful and pervasive that in the not too distant future it will provide an explanation in principle of all phenomena in the world of nature including man, even human consciousness in all its manifestations" (page 7). So, after a first introductory lecture, Eccles proceeds through the "Origin and Evolution of the Universe", the "Planetary System and Planet Earth", the "Origin of Life and Biological Evolution", to "Human Evolution: The Story of Cerebral Development". It is in the second half that we come to the real speciality of the house: "Cultural Evolution with Language and Values: The Human Person"; "The Creation of a Self"; "Structure of the Neocortex: Conscious Perception"; "Learning and Memory"; and "The Mind-Brain Problem"'.

To the scientific layman the story which Eccles tells in his first half is fascinating, though here and elsewhere to follow him those handy Penguin dictionaries of the sciences: if he has succeeded in his attempt "to present scientific material ... with a minimum of technicality", then one must pray to be spared the failures.

The Gifford aspect appears at once in "the Big Bang story as suggesting the operation of a supernatural Creator" (page 15); although it is curious that Eccles mentions only in an aside the notion of a Creator upon whom - whether or not, $\mathrm{He}$, or Universe off - it continues to be always absolutely dependent. After all, it was precisely and only continuous creation in this theological sense which St Thomas insisted could be known on the basis of natural reason, without benefit of revelation.

Two other Gifford points stressed in the first half are the unpredictable chanciness of the emergence of life, and of the actual course of biological evolution; and the fact that the whole cosmological story would have had to be very much as it has been if beings capable of knowing that story were going to become part of it. About the former Eccles maintain, and surely he is right, that "There is no predictable line of evolutionary development"' (page 49). It seems to be as true of the evolutionary biologist as of the human historian that most of his most closely requires frequent consultation of She, 'in the beginning' also started the important explanations are of how something was possible, rather than of why it was inevitable. No doubt other readers will share my own pleasure in two pieces of Eccles mischief: the suggestions that the most primitive mammals "brought about the dinosaurs' downfall by preying on their eggs"' (page 58); and - of "the attempt to communicate with super-intelligent humanoids in our galactic system" - that it is "highly likely that this romantic project will be kilted by boredom"' (page 73).

In wondering what to make of the second of the two points stressed in the first half we must give some weight to the point, which Eccles does not notice, that these conclusions are derived only for a Universe obeying the same fundamenta! laws of nature. The argument is that "If we economise and have the Big Bang producing the mass for one galaxy of $10^{11}$ stars, which is still an immense universe", then, given what we now know of the fundamental laws of the actual Universe, "the time from Big Bang to Big Crunch is reduced to one year" (page 28). But a Creator, having it in mind to furnish his creation with potential knowers, would not, presumably, be restricted either to or by any actual or possible natural laws.

In his rather longer second half Eccles is at least equally fascinating. In lecture 6 be begins by contending, as is surely correct, that "cultural evolution is exclusively human' (page 98). This and much of the later discussion is presented in terms of Popper's distinction between "three Worlds: World 1, the matter-energy of the cosmos; World 2 of all subjective experiences; and World 3, which is the cultural heritage of mankind"' (page 98). The reader needs to be aware always, as their spokespersons so often are not, that the second and third of these can be identified only as aspects of the first. We have, that is to say, no knowledge of any kind of consciousness other than the consciousness of organisms; and perhaps we cannot even give sense to talk of any consciousness that is not thus rooted in the matter-energy of World 1 . The whole cultural achievement of World 3 is likewise embodied in, and inseparable from, such incontestably World 1 objects as buildings, books and computer tapes.

In the rest of this lecture Eccles considers the enormous importance of language and - what could not exist without language - the self-consciousness which is so much more than mere consciousness. As one expression of his constant and most welcome concern to resist the 1984 which is "engulfing more and more of our planet" (page 237), and after crediting to the Sumerians the two incomparably important inventions of both writing and the wheel, Eccles remarks that for most of its history Sumer "was an amazingly open and tolerant society" (page 114); though it does not occur to him that those market 
interests which he was earlier inclined to chide might have been one necessary condition of this tolerance (page 110).

Lecture 7 examines "the role of World 3 in producing the next generation"; making much, but never too much, of the crucial fact that it is thanks to this that "The creation of a cultured person" can now "be accomplished in a few years", whereas "it took at least 50,000 years to create a high civilisation" (page 123). This chapter contains one section which will especially delight any philosopher who has ever faulted Hume's Treatise of Human Nature for its "paralytic's eye view of causation": Eccles tells of experiments with kittens in gondolas which show that exploratory learning will not take place without active movements by the learner (page 132).

Lecture 8 on "Conscious Perception" constitutes necessary preparation. In lecture 9 on "Learning and Memory" the thesis is that memory is essential to anything deserving to be called knowledge: "Without memory there could not be a knowing of existence" (page 180). In lecture 10 Eccles wants to construe mind and brain as "independent entities, the brain being in World 1 and the mind in World 2 (Fig. 61)', and to urge that these are both entities which "somehow interact, as illustrated by the arrows in Figure 10-2", (page 212).

But this, as the rally-drivers say, is going a bit quick. For all our ordinary talk about minds, ordinarily understood, is just talk about certain sorts of things which some creatures of flesh and blood can and do do or suffer. To say that, for instance, she has a first-class mind just is to say that she is capable of operating at that high academic level. So if anyone wants to hypothesise some independent entities to be called minds, he has first to provide some account of how such entities are to be identified and individuated. For minds in the common everyday sense of the word are not what is required: they are not, that is to say (logical) substances things which, like chairs and tables and unlike grins and tempers, could significantly be said to exist separately and in their own right. To speak of her firstclass mind surviving her death and cremation would, in the everyday sense of 'mind', be about as sensible as speaking of the grin on the face of Alice's Cheshire Cat outlasting the cat of whose face it was a configuration. On the other hand, much of the history of philosophy since Descartes can be read as showing how difficult if not impossible it must be to think up a notion of minds as immaterial substances; which could be identified as subjects of discourse, re-identified through time, and individuated one from another.

Antony Flew is Professor of Philosophy at the University of Reading, $U K$.

\section{Precious cult of scientific knowledge}

\section{Martin Pollock}

Paradoxes of Progress. By Gunther S. Stent. Pp. 231. (Freeman: San Francisco and Reading, UK, 1978). Hardback £8; paperback $£ 3.90$.

THIS is a collection of articles on modern science, already published over the past ten years or so and now strung together, a little forcedly perhaps, under a title which can serve a multitude of themes. It is therefore, inevitably, somewhat of a ramble. The common thread is Professor Stent's own idea of what is happening to our precious cult of scientific knowledge, where it is going and what its principles mean, or should mean, for us. His opinions are worth studying, though cramped by a rather awkward style of writing and even if - or especially if - one does not agree with them. The problems he raises and the questions he asks are those which most scientists do not even like to think about, let alone try to answer.

All the essays are worth reading in their own right, although two of them - a review of Jim Watson's Double Helix and an analysis of "Prematurity and Uniqueness in Scientific Discovery" - stand rather apart from the rest, being of borderline relevance to the central issue. Three are of outstanding interest. These are: (1) "The Dilemma of Science and Morals" which discusses the many desperate problems of how our continuously expanding knowledge should be applied practically and includes a brief but fascinating comparison between the science and technology of classical China and western scientific philosophy; (2) "Limits to the Scientific Understanding of Man", being essentially a clear-cut criticism of positivism and its later manifesations in the form of simplistic acceptance of a reality that is "built on cumulative experience" alone and is now referred to as "Scientism"; and (3) "The Decadence of Scientism" ('Decline' might have been a more appropriate word), which discusses a neo-Kantian basis for understanding and a practical morality that recognises the impossibility of true objectivity or valuefree conclusions, and involves adopting what is now often referred to as a "Structuralist" and anti-beviourist approach to thinking and acting; this itself depends on analysis of "deep structures" beneath the superficialities to which alone our senses are directly responsive.

According to Stent, science, as we now know it, is on the way out. The spirit of "Faustian man" who believes in "progress", and outward striving (defined as the "will to power") is on the wane and yielding diminishing returns; it is anyway self-limiting because it seeks, and to a large extent obtains, a sense of security which quenches the thrust for more power. Faustian man, born in the ages of enlightenment of the seventeenth and eighteenth centuries and reaching maturity in the nineteenth where the solution to all problems was viewed in the context of a continuously progressive increase in knowledge and power over the outside world, is on his death bed. His spirit will be succeeded by something similar to the Polynesian-based dream of a life of ease but without grand ambitions, a rejection of the idea of "progress" and materialistic sophistications and an acceptance of the Zen principle that the recognition of subjective sensation is the only reality. The "noble savage" is not a fancy directed backwards to the distant past, but something to anticipate in the years to come. The different articles share a common theme by illustrating the problems and paradoxes which herald the end of our era. And the author, who has rightly emphasised the many analogies between science and the arts, believes that similar factors are involved in the decline of the arts which have now lost all style and discipline, become totally "freed" and will have to start again with a new impulse.

One of the first signs of the end was, according to Stent, the "beatnik" movement in Berkeley of the late 1950s and (to a later and lesser extent) the hippy creed of the 1960s. Amongst scientists themselves, the relevant factors include a growing sense of the limitations to the objectivity of our observations and conclusions and increasing estrangement between our intuitive common sense and what we have to accept as most appropriate explanations; in particular, the principle of indeterminism in physics, which is equivalent to saying that like causes do not necessarily have like effect would seem to undermine the fundamentals of scientific explanation.

Stent also refers to a phenomenon described by Mandelbrot termed "secondstage indeterminism" where probably random events, such as "noise" in an organised system, theoretically able to be eliminated by a statistical approach, nevertheless seem on analysis for limited periods, to conform to certain laws of fluctuation (for example, in coin tossing experiments). This problem is the old one of how to decide when to introduce the concept of chance and what the idea of randomness really means - a dilemma which has faced scientists for very many years. To what extent, for instance, are the structural patterns we think we see around us simply illusions, based on too superficial and prematurely completed analysis of a series of events that require an impractically long period of study for 